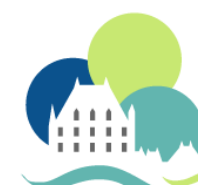

ISCAR 2017

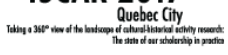

\title{
Developing the Ideas of the Scientific School of L. S. Vygotsky: Scientific Publications of the Journal "Cultural and Historical Psychology" (2005-2016)
}

\author{
Anna A. Shvedovskaya \\ Federal State Budgetary Educational Institution of Higher Education \\ Moscow State University of Psychology and Education \\ Moscow, Russia
}

\begin{abstract}
The article presents the analysis of the development of the ideas of L.S. Vygotsky's school using the example of the publications in the international scientific journal "Cultural and Historical Psychology" (for the period 2005 through 2016). Over the period from 2005 to the end of 2016, 595 articles of 524 authors from 32 countries have been published in the journal "Cultural and Historical Psychology." The study of the subjects of the articles published in the journal was held within the framework of the following criteria: scientometric publication indicators; group of authors; themes of the publications; relevance of the articles for their readers. The research uses the following sources: Russian Science Citation Index (RSCI); repository data of the psychological editions of https://psyjournals .ru/; report data on the activities of the journal "Cultural and Historical Psychology." The citation frequency of the journal's publications peaks in 2007, 2009 and 2006. Empirical findings comprise major part of the publications. The most developed areas are the studies of speech and thinking, personality, and communication.
\end{abstract}

Keywords : Cultural and historical psychology; L. S. Vygotsky; Bibliometric analysis; Web of Science; RSCI; Speech; Personality; Socialization; Scientific publications. 
The Regulation of the Government of the Russian Federation No.301 dd. April 15, 2014 "Concerning the approval of the Government program of the Russian Federation 'Development of Science and Technology' for 2013-2020" (revised version) provides for solving the task of re-establishment of the leading positions of the Russian fundamental science in the world arena ${ }^{1}$. The respective Decree of the President of the Russian Federation No.599 dd. May 7, 2012 "Concerning measures to implement state educational policy" mentions the increase in the share of publications by Russian researchers in the total number of publications in international scientific journals indexed in the database "Web of Science" up to $2.44 \%^{2}$. According to the analytical database services Web of Science, the share of publications by Russian researchers in the total number of publications in scientific journals indexed in the database Web of Science was 2.1-2.11\% in 2013-2014. The index by the end of 2015 rose to $2.31 \%$. In 2013, the number of publications was 29,019. 30,097 publications were issued in 2014, and 33,628 publications in $2015^{3}$.

At the same time, the share of Russian scientific periodicals in the Web of Science system based on the humanities and social sciences is extremely low. Over a long period of time, there have been only two Russian periodicals presented from the scientific periodicals in "Psychology" in the Web of Science system. This indicates the timeliness of including more of the leading scientific periodicals of the Russian Federation in the Web of Science system in order to raise awareness of the results of the Russian research in psychology and related fields all over the world.

In this context, it is extremely important to solve problems of carrying out substantial and scientometric analysis of the indicators as to the leading Russian scientific humanitarian publications. The international journal "Cultural and Historical Psychology" is the best known specialized Russian-language scientific publication in the field of cultural and historical and activity-related psychology. The year 2016 has been declared the International Year of Lev Semenovich Vygotsky, the founder of the school of cultural and historical psychology. The "Cultural-Historical Psychology" journal is the only Russian scientific periodical, the content of which fully meets cultural, historical and activity paradigm. The journal has been published in Russia by Moscow State University of Psychology and Education since 2005.

1. Postanovlenie Pravitel'stva RF ot 15.04.2014 No 301 «Ob utverzhdenii gosudarstvennoi programmy Rossiiskoi Federatsii "Razvitie nauki i tekhnologii" na 2013-2020 gody» [Electronic resource] [RF Government Resolution dated 4.15.2014 number 301 "On approval of the Russian Federation" Development of science and technology "for 2013-2020 state program"]. URL: http://www. consultant.ru/document/ cons_doc_LAW_162175/ (Accessed 18.09.2016).

2. Ukaz Prezidenta Rossiiskoi Federatsii ot 07.05.2012 g. No 599 «O merakh po realizatsii gosudarstvennoi politiki v oblasti obrazovaniya i nauki [Electronic resource] [Presidential Decree of 07.05.2012, No 599 "On measures for implementation of the state policy in the sphere of education and science]. URL: http://kremlin.ru/acts/bank/35263 (Accessed 18.09.2016).

3. Otchet o khode realizatsii i otsenke effektivnosti gosudarstvennoi programmy Rossiiskoi Federatsii «Razvitie nauki i tekhnologii» v 2015 godu (utochnennyi) [Electronic resource] [Report of Progress on the implementation and evaluation of the effectiveness of the state program of the Russian Federation "Development of Science and Technology" in 2015 (revised)]. URL: http://government.ru/info/23028/ (Accessed 18.09.2016). 
It should be noted that the "Cultural-Historical Psychology" journal was included in the main international databases, such as PsycINFO Journals Coverage (APA), European Reference Index for Humanities (ERICH PLUS), EBSCO publishing, Ulrich's Periodicals Directory, DOAJ, Russian Science Citation Index. The Higher Attestation Commission (HAC) recommended the Cultural-Historical Psychology Journal at the Ministry of Education and Science of the Russian Federation in the List for publication of scientific results of thesis research included in the List recommended fr publication by the Monash University of Australia. The National Research University "Higher School of Economics" (NRU HSE) has chosen the "Cultural and Historical Psychology" journal to be included in the list of B-category publications (mid-level conditional group), which are recommended for publication to the employees of NRU HSE in "Psychology" (2015). Since January 2015 the journal has been included in the basic list of magazines (Core Collection) of the international database Web of Science (WoS) Emerging Sources Citation Index (ESCI), where it has been inexed since the date of its first issue in $2015^{4}$.

The editorial team and the editorial board of the international scientific journal "CulturalHistorical Psychology" includes 37 representatives from Russia (23), Australia, Denmark, Finland, the USA, Switzerland, Israel, Great Britain, and Cuba (14). Maximum $h$-index of the members of the editorial team: WoS -41 , RSCI - 38 (while maximum $h$-index in the "Psychology" sector is 55).

The tenth anniversary of the "Cultural and Historical Psychology" journal is the reason to analyze the development of Vygotsky's school. We have conducted a study of the subjects of the articles published in the journal in terms of the following criteria: scientometric publication indicators, group of authors, topics of the publications, and relevance of the articles for their readers (Shvedovskaya, 2016; Shvedovskaya \& Meshkova, 2015). The following sources have been used for the research: Russian Science Citation Index (RSCI), repository data of the psychological editions of PsyJournals.ru., report data on the activities of the journal "Cultural-Historical Psychology" (Shvedovskaya \& Meshkova, 2016).

According to the Russian Science Citation Index, "Cultural and Historical Psychology" journal ranks $21^{\text {st }}$ among 203 psychology journals as to the number of citations per year. It is essential to note that the editorial policy of the publication is aimed at integrating the "Cultural and Historical Psychology" journal into the international professional context. According to the Journal Scholar Metrics of Art, Humanities, and Social Science journals (data obtained from Google Scholar), 10 psychology journals out of the total number of 1,032 journals are from Russia. "Cultural and Historical Psychology" ranks $2^{\text {nd }}$ among them ( $h$-Citation - 71, for the period of 2010 through 2014), and $792^{\text {nd }}$ in the overall world ranking 5 .

Over the period from 2005 to 2016, 595 articles of 524 authors from 32 countries have been published in the journal "Cultural and Historical Psychology." Three publications or more

4. Master Journal List Thomson Reuters [Electronic resource]. URL: http://ip-science.thomsonreuters .com/mjl/ (Accessed 18.09.2016).

5. Journal Scholar Metrics, Art, Humanities, and Social Science Journals [Electronic resource]. URL: http: // www . journal-scholar-metrics . infoec3. es (Accessed 18.09.2016). 
were presented by authors from the following countries: Germany, USA, Great Britain, Brazil, Poland, Italy, Canada, Finland, Mexico, Estonia, Belarus, and Latvia. According to the data provided by RSCI, the majority of the Russian authors are representatives of the Russian universities $-82 \%$ of the authors, while the total number of organizations is 81 . Most of the organizations to which the authors are affiliated are inside the top hundred scientific and educational institutions of the Russian Federation in terms of $h$-index: the values are 69 to 218 out of total 3,317 (Fig. 1). Out of 524 authors: the works by $70 \%$ of them were published for the first time; $24.3 \%$ authors published two to five articles; $5.7 \%$ authors published more than five articles ${ }^{6}$.

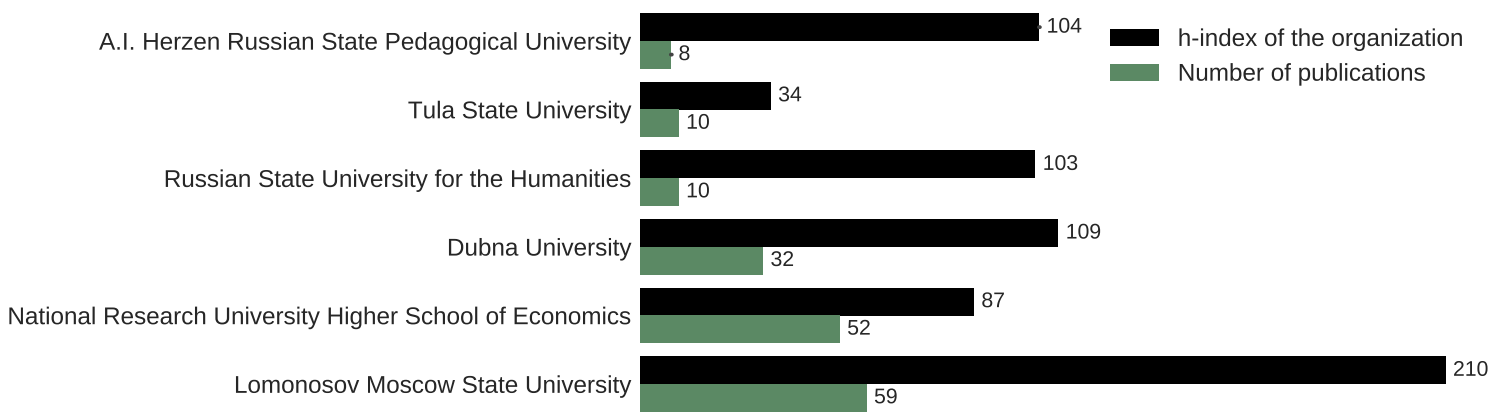

Figure 1. Affiliation of the authors of the "Cultural and Historical Psychology" journal, whose works have been published over the period from 2005 through 2016.

In 2016, the indicator of citations for the articles published in the "Cultural and Historical Psychology" journal was 1,356 (RSCI). The distribution of citations by year shows that articles published in 2007, 2009, and 2006 are among the most cited ones. At the same time, the studies published in the "Cultural and Historical Psychology" journal are frequently cited by the specialized journals of the following branches: psychology, education, medicine and philosophy ${ }^{7}$.

If we refer to the data presented by RISC, the content of journal publications by key directions (keywords) is distributed as follows (Fig. 2).

Based on the results of content analysis of publications over 10 years in the "Cultural and Historical Psychology" journal (the total number of publications being 316), the number of empirical, theoretical, and other publications was calculated ${ }^{8}$. It was demonstrated that empirical publications predominate -316 publications, followed by theoretical publications -199 , and others -80 (Fig. 3).

6. Nauchnaya elektronnaya biblioteka, setevoi resurs [Scientific electronic library]. URL: http://elibrary .ru (Accessed 18.09.2016).

7. Idid.

8. Portal psikhologicheskikh izdanii [Electronic resource] [Portal of psychological publications]. URL: http://psyjournals.ru (Accessed 18.09.2016). 


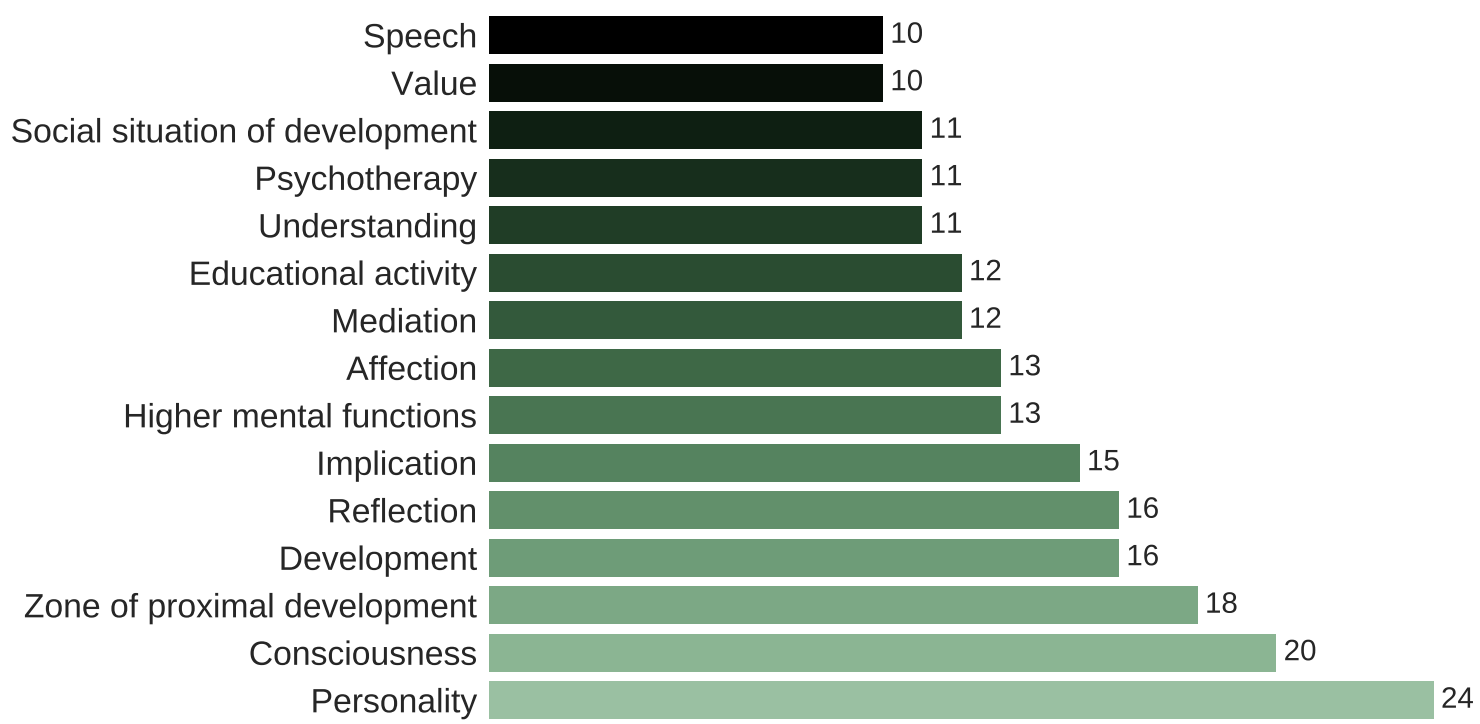

Figure 2. The number of publications of the "Cultural and Historical Psychology" journal published over a period from 2005 through 2016 per one thematic direction (according to RSCI)

Archives, reviews, interviews, anniversaries

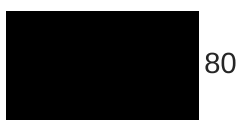

Theory, methodology, discussion

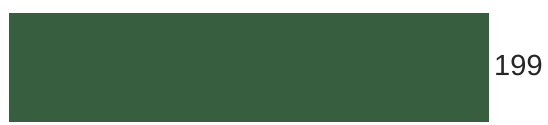

Empirical studies

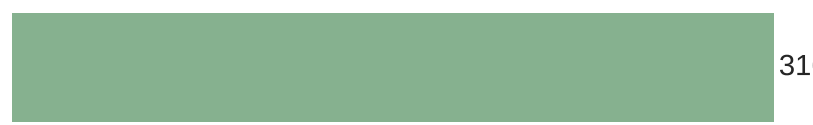

Figure 3. The number of theoretical, empirical, and other publications of the "Cultural and Historical Psychology" journal published over a period from 2005 through 2016. 
There were 12 thematic units allocated in empirical studies.

1. Speech and thinking (17\%).

2. Socialization, communication, attitude (14\%).

3. Education (9\%).

4. Perception (6\%).

5. Memory (6\%).

6. Special and neuropsychology $(9 \%)$.

7. Personality, motivation, emotions (11\%).

8. Ethnocultural research (3\%).

9. Family (9\%).

10. Religious identity (4\%).

11. Types of activities, interests (8\%).

12. Art, creativity $(4 \%)$.

The intensity of thematic units in empirical research is shown in Fig. 4.

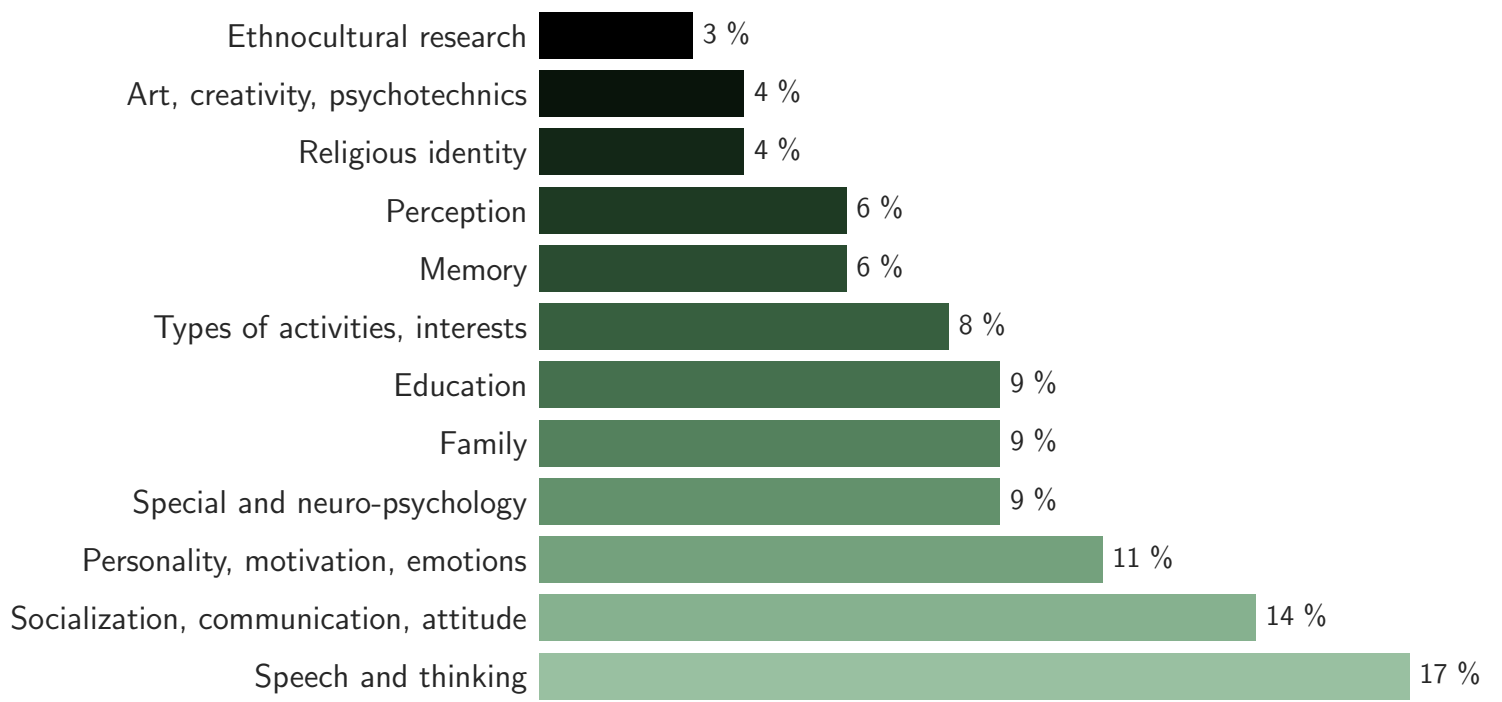

Figure 4. Intensity of the themes as to empirical research of the "Cultural and Historical Psychology" journal published over a period from 2005 through 2016.

According to the altmetrics of the Psyjournals.ru repository, the article which appeared to be most relevant for the readers of the "Cultural and Historical Psychology" journal 
deals with the theme of burn-out (2010), the number of downloads of the PDF-file with the article is $2,123^{9}$.

The publication on the interaction of social, linguistic, and conceptual experience (2014) - 1,018 downloads, and the publication on the basics of logopsychology (2008) - 926 downloads, are the top two most sought-after materials.

Let us elaborate on the selected topics and review the basic content of the publications presented in the research.

\section{1. "Speech and Thinking" Research Unit}

Aspects of thinking development in disadvantaged groups (orphans, working children and adolescents); mediation; syncretism; development of concepts; development of the perspective constructions in childhood; cognitive functions in late adulthood; strategies to address cognitive tasks; age dynamics of development of creative (or productive) thinking; the role of vision of preschool children of metacognitive knowledge in cognitive activity; special aspects of the categorical color perception in children with impaired speech development; mastering language by children for orientation in emotional relationships and conditions; intelligent operations and speech disintegration; activating the speech activity in the mental retarded; sign systems to substitute natural language in the early stages of mastering speech with different variants of dysontogenesis; modelling in the development of hypotheses.

\section{2. "Socialization, Communication, Attitude" Research Unit}

Attitude toward people with disabilities, socially desirable ways of acting and personal wellbeing, emotional well-being of the individual and sociability, the effectiveness of means of communication used by the parents of deaf children, and intellectual development of the child; suicidal behavior in the student population and emotional maladjustment; interpersonal relationships of adolescents with deviant behavior from socially disadvantaged families enrolled in special schools; social isolation of academically unsuccessful teenagers experiencing financial difficulties and family problems in regular school; teenage aggression and the nature of parent-child relationship; social factors and physical perfectionism in young people; identification of objects of attention and understanding of the context of the communicative situation; motivational profiles that contribute to the socialization of adolescents.

9. Portal psikhologicheskikh izdanii [Electronic resource] [Portal of psychological publications]. URL: http://psyjournals.ru (Accessed 18.09.2016). 


\section{3. "Education" Research Unit}

Academic achievements of children and interaction of teacher with their class in a classroom; age peculiarities of voluntary regulation of children's activity in the transition to the systematic training; training teachers for primary schools in the context of the introduction of the new Federal State Education Standard; the dynamics of individual motives for learning in children throughout the primary school; use of symbolic and iconic means (schemes and models) in training during the development of the new content.

\section{4. "Activities, Interests, Subculture" Research Unit}

The double-contact mechanism of a game; animation as a source of experience and awareness of moral conflicts, age-related addressing of cartoons; peculiarities of entry into adulthood in a specific social context in off-field subculture; mass culture and the formation of children's favorite images; the role of media in shaping the body image and its ideal; collecting as a psychological phenomenon.

\section{5. "Perception" Research Unit}

Physical attractiveness; deficit of visuospatial functions; the environmental factor and features of spatial perception; eye movements in patients with schizophrenia in the perception of the "silent" video of social interaction; perception and understanding of architectural space.

\section{6. "Memory" Research Unit}

The phenomenon of ignoring information when fulfilling mnemonic tasks; activity (motivational) regulation of mnemonic processes (by the example of memories of the terrorist attacks); the effectiveness of involuntary memorization of words; nostalgia as a special kind of emotional memory; reflexive organization of experience as a principal memory function; study of the arbitrary memory in children with various types of deviant development.

\section{7. “Personality, Motivation, Emotions” Research Unit}

Intrapersonal conflicts in adolescence; initiative; fears (school fears); moral development of the individual and the dynamics of the individual values in the context of the social environment; the critical attitude to oneself as neologism in the structure of the self-concept of primary school-aged children; development of personality in people with disabilities as development in difficult conditions; involvement of bodily sensations in the understand- 
ing of emotions; personal autonomy and moral orientation of adolescents defined with the priority values of justice or concerns; biographical reflection, sense-making and selfregulation; self-control as a personality-motivational resource of activity and psychological well-being.

\section{8. “Ethno-Cultural Studies" Research Unit}

Time perspective in various cultures; preferences of the principle of fairness and the principle of caregiving in cultural groups; adaptation of different cultures in the conditions of educational institutions; relevant social environment and ethnic identity; comparative etymological analysis of naming emotions in various languages; motivation, ethno-cultural continuity and strategies of acculturation and ethnic minorities; trust and accultural strategies of ethnic minorities and migrants; peculiarities of moral grounds in adolescents from different countries.

\section{9. “Clinical Psychology, Special Psychology, and Neuro-Psychology" Research Unit}

Neuropsychological approach to the improvement and development of mental functions in children with severe learning difficulties; features of the formation of functional hemispheric asymmetry and higher mental processes; training and support for special children (trisomy 21 syndrome, epilepsy); neurorehabilitation of higher mental functions in patients with brain injuries; formation of motor coordination in children with normal and abnormal development; analysis of the zone of proximal development in children with various forms of dysontogenesis; the development of gross and fine motor skills in children with schizophrenia.

\section{0. "Family" Research Unit}

Family orientation in the minds of girls from 15 to 22 years of age; socio-economic characteristics of a family and a child's temperament during infancy and early childhood; microsocial resources (support of the family and relatives, satisfaction with this support), and psychological resources of sustainability and self-identity; psychosemantic systems of family purposefulness; a mother's internal position of those participating in an IVF (in vitro fertilization) programme; the psychosemantic system of family purposefulness in men. 


\section{1. "Religious Identity" Research Unit}

Attitude toward death in cultural centers with traditionally predominant Christian denominations; the vision of young students of atheism and the personality of atheist; religious identity of students of the Buddhist denomination.

\section{2. "Art, Creativity" Research Unit}

Implementation of dance movement techniques in complex speech therapy and psychocorrection in stutterers; the use of the themes of life and death by the teens from 14 to 16 years of age in their written word; the mascot as psychological tool.

Consequently, the themes related to the research of consciousness and personality are predominant among all publications of the "Cultural and Historical Psychology" journal from 2005 through 2016; the themes related to speech, thinking, socialization, and personality are predominant among empirical studies. The majority of the authors are representatives of Russian universities inside the top hundred scientific and educational institutions of the Russian Federation in terms of the $h$-index. One may say that the policy of integrating the efforts of scientific and professional community around the goals of studying, preservation, and development of the ideas of cultural and historical psychology brings its tangible results, and it is being actively supported by the "Cultural and Historical Psychology" journal.

\section{References}

Shvedovskaya, A. A. (2016). Prospective study of the L. S. Vygotksky's scientific school on pages of journal «Cultural-Historical Psychology»: Results of the decade of work. In The materials of international symposium Scientific School of L. S. Vygotsky: Traditions and Innovations (pp. 97-101). Moscow.

Shvedovskaya, A. A., \& Meshkova, N. V. (2015). Bibliometric analysis of the journal [psychological science and education]. Psikhologicheskaya nauka i obrazovanie [Psychological Science and Education], 20(4), 108-116. doi: 10.17759/pse.2015200411

Shvedovskaya, A. A., \& Meshkova, N. V. (2016). Bibliometric analysis of the journal "cultural-historical psychology". Kul'turno-istoricheskaya psikhologiya [CulturalHistorical Psychology], 12(1), 106-115. doi: 10.17759/chp.2016120112 